\title{
Impact of the first COVID-19 lockdown on scientific productivity and workload in Denmark: a gender analysis
}

Claire Francesca Meehan ${ }^{1,2^{*}}$, Ea Høg Utoft ${ }^{1,3^{*}}$, Christine Parsons ${ }^{1,4^{*}}$, Vanessa Jane Hall ${ }^{1,5}$, Mette Bendixen ${ }^{1,6}$, Ida Vogel ${ }^{1,7}$, Katherine Patrice Gill ${ }^{1}$, Emma Louise Louth ${ }^{1,8+}$

*Contributed equally

+ Corresponding author

\section{Affiliations:}

1. The Danish Association for Women in Science (DANWISE), Denmark

2. Department of Neuroscience, Faculty of Health and Medical Sciences, University of Copenhagen, Denmark

3. Danish Centre for Studies in Research and Research Policy, Department of Political Science, Aarhus University, Denmark

4. Interacting Minds Center, Department of Clinical Medicine, Aarhus University, Denmark

5. Group of Brain Development and Disease, Section Pathobiological Sciences, Department of Veterinary and Animal Sciences, Faculty of Health and Medical Sciences, University of Copenhagen, Denmark

6. Department of Food and Resource Economics, University of Copenhagen, Denmark

7. Department of Clinical Medicine, Aarhus University, Denmark

8. Danish Research Institute of Translational Neuroscience (DANDRITE), Department of Biomedicine, Aarhus University, Aarhus University, Denmark

Running title: COVID-19 on science workload in Denmark

\section{Acknowledgements:}

We would like to sincerely thank the entire DANWISE team for all of their hard work and contributions to our organization. This manuscript represents one of the many projects that we work on together as a team and could not be achieved without every member.

We are also indebted to Johanne Victoria Nedergaard Jensen from the Copenhagen University "Uniavisen" and Maria Mortensen for their assistance in advertising the online survey. 


\section{Abstract}

The first wave of the COVID-19 pandemic and subsequent lockdown of Universities globally in the spring of 2020 appears to have had a negative impact on female academics in countries studied to date. Denmark is an exemplar country with clear legislative practices to support gender quality, and differences between men and women with regards to unpaid house and care work are less substantial than many other places. It is largely unknown whether Danish academics experienced the same level of COVID-19-related disruption to productivity and whether women, or academics with children in general experienced more serious disruption. To investigate the local effects of the lockdown in Danish academia, we (i) performed an analysis of preprints in a single academic field and (ii) surveyed academics employed at Denmark's largest University. We found that parents with young children worked less hours per day during the lockdown than academics with older or no children and that this effect was more pronounced in women with young children. The vast majority of both male and female scholars with teaching responsibility reported more time spent on teaching. A larger proportion of junior academics felt their productivity decreased compared to senior academics. Additionally, analyses of the number self-reported submitted grants and manuscripts did not show any differences differ by gender or career level. However, the gender gap did increase during the first month of the lockdown with respect to the number of manuscripts submitted to preprint servers. This study contributes to emerging data on the impact of lockdowns on academic productivity and highlights the negative impact on parents with young children that is exacerbated in women with young children. 


\section{Introduction}

Denmark ranks highly on indices concerning equality in the home. In 2018, an OECD study surveyed 28 countries and found that men in Denmark spend the most time on unpaid work, such as household chores and grocery shopping compared to the other countries (OECD, 2018). Denmark also has legislative policies allowing both fathers and mothers to share the parental leave of 52 weeks in total. A substantially government-subsidized childcare system is also available for families with children. In addition, more women obtain a university education in Denmark than men (Danish Ministry of Education and Science, 2020). Globally, the unequal distribution of domestic labour and childcare is often cited as an explanation for the gender gap in senior management positions. Given the Danish data on domestic labor and childcare, it could be expected that Denmark's gender gap in leadership positions might be smaller than in other countries.

However, the actual data presents a contradictory picture. Denmark ranks surprisingly low with respect to female representation at the legislator, senior officials and manager level, ranking 95th internationally (World Economic Forum, The Global Gender Gap 2018). This pattern is also observed in science, with only 34\% of associate professors and $23 \%$ of full professors being women as of 2018 (Danish Ministry of Education and Science, 2020). These results are far behind many other countries, including Denmark's neighbors in Scandinavia, Sweden (46\% and 28\%), Finland (50\% and 30\%) and Norway (48 \% and 31\%) (Danish Ministry of Education and Science, 2020). While Denmark has clear legislature and government-financed childcare schemes, the traditional gendered family structures still persist. Although Danish men perform more housework relative to men elsewhere, women nonetheless still take on more house and care work than men (Cevea, 2016). Women also take more parental leave, despite the possibility to equally share it (Statistics Denmark, 2019a).

There have been numerous discussions about the disproportionate burden of the pandemic on women in general, and a concern that the COVID-19 lockdowns will amplify existing gender inequalities in academic (Hansen 2020, Malish et al 2020, Oleschuk, 2020). Globally, data suggests that female scientists may have been disproportionately affected by the COVID-19 lockdowns that occurred during the first wave of the pandemic in 2020. In Denmark, the lockdown prevented 
academic researchers from entering their work environments for two months, from 15th March to 15th May 2020. Scientific productivity is frequently judged by publication rates, which is one of the main metrics used to evaluate scientists for funding, promotion and salary negotiations. In Denmark, university hiring committees and granting bodies typically prioritize publication rates when selecting candidates. As such, a reduction of academic productivity and output during COVID19 lockdowns is predicted to have serious consequences on career progression.

An initial analysis of publication rates found an overall increase in manuscript submissions to the preprint servers arXiv and boiRxiv from 1st March to 30 April 2020 compared with both the January to February 2020 or the same period in 2019 (Frederickson et al 2020). However, this increase was more pronounced for male authors compared with female authors, irrespective if analyzed for all authors, single authors or for corresponding authors. These results have been corroborated by further studies focusing on author position showing a decrease in female first author submissions across a larger range of preprint servers (including EarthAri, medRix, SoiArXiv and NBER) in March and April 2020 compared to the same months in 2019 (Vincent-Lamarre et al 2020) and a decrease in female corresponding authors in medRix relative to males (Wehner et al 2020).

While measures of pre-print uploads provide important insights into productivity, they do not provide a comprehensive evaluation of the impact of the pandemic. Pre-print-based analyses underestimate the pandemic effects, as many of the manuscripts were likely to have been in preparation before the lockdown commenced. Furthermore, these global analyses do not account for the different time windows of national lockdowns. To examine pandemic-specific effects, some analyses have examined the number of manuscripts published specifically on COVID-19 because the major workload for these (including experimental work, analyses and manuscript preparation/submission) would be more restricted to the COVID-19 lockdown period. An analysis of papers listed in Pubmed mentioning COVID-19 revealed that, women constituted fewer first and last authors (29 and 25\% respectively, Pinho-Gomes et al 2020). When compared with an analysis of medical publications from 2017 where females represented $40 \%$ of first authors, and $27 \%$ of senior authors, these figures appear to reflect considerable reductions (Nielsen et al 2017). 
Consistent with this, female first authors constitute a smaller proportion of COVID-19-related submissions to preprint servers than in other research areas (Vincent-Lamarre et al 2020).

Overall, analyses of preprints and COVID-19-related research suggest disproportionate negative effects of the COVID-19 pandemic on women in academia. In this study, we therefore asked: has the pandemic had similar effects in Denmark relative to the global picture? Or does the greater equality in unpaid work in Danish homes protect female researchers from the gender disproportionate effects of COVID-19 on productivity? It is also unclear what happened to the distribution of childcare and household tasks when state-assisted child care facilities closed for one month during the lockdown. Despite the high levels of equality in Denmark, it is important to note that a high number of children live with only one parent in Denmark ( $29 \%$ compared with an EU average of 15\%), and in these circumstances, the burden naturally falls more heavily on one parent.

Two different approaches were made to investigate the COVID-19 pandemic's effects on female academics in Denmark; The first approach consisted of an analysis of manuscript submissions to BioRxiv, the preprint server for the biological sciences, with a focus on corresponding authors from Danish institutions over a two month period during the first lockdown (15th March 2020 to 15 May 2020). Subsequently, we distributed a survey to researchers at the largest university in Denmark, The University of Copenhagen, to estimate productivity. We defined "actual productivity" as the numbers of manuscript and grant application submissions and "perceived productivity", as the amount of hours spent working including hours designated to teaching. In addition, participants were asked to estimate their own productivity during the lockdown compared to the same time period the year before. Preliminary results have been discussed in a correspondence piece in Nature (Bendixen and Hall 2020). Here, we present and discuss the full data set.

The paper proceeds as follows: First, we introduce our methods, followed by a systematic review of our empirical findings. Subsequently, the discussion offers a contextualization of our empirical findings, based on feminist scholarship, under three subheadings: family structures, academic organizing, and the Danish context vis-à-vis Denmark's international reputation. In the concluding 
remarks, we tie the study together and discuss its implications for institutional gender equality efforts and future research. 


\section{Materials and Methods}

\section{Analysis using Preprint surveys}

We catalogued author information for all preprints submitted to BioRxiV from the $15^{\text {th }}$ of March to the $15^{\text {th }}$ of May 2019 and the same months in 2020 (as described by Frederickson et al, 2020, https:/github.com/drfreder/pandemic-pub-bias/blob/master/README.me). These dates correspond to the first two months of lockdown in Denmark. Open-source software, Genderize (https://github.com/miriamposner/derive gender/blob/master/derive-gender-from-a-column-offirst-names.md) was used to estimate the number of male and female corresponding authors from the total submissions. Finally, we extracted any corresponding authors with a Danish affiliation to determine if Danish authors showed the same trends as the rest of the international BioRxiV submissions.

\section{Survey}

An online survey was performed using the platform "SurveyMonkey", including questions regarding actual and perceived productivity and time spent on domestic and teaching responsibilities (see appendix Table 1). We recruited respondents from the University of Copenhagen via emails to departments participating in equality programs at the University and via the online University newspaper, Uniavisen. Survey responses were collected over a period of 35 days (the $20^{\text {th }}$ May to $24^{\text {th }}$ June 2020).

\section{Data analysis}

Statistical analysis was performed using GraphPad Prism 8 (GraphPad Software, USA). Data was analyzed by Chi squared analysis or two-way ANOVA. 


\section{Results}

The COVID-19 lockdown disproportionately affected preprint submissions for female corresponding authors

The data analysis shows that the total submission rate for corresponding authors is higher in 2020 compared to the corresponding months in the previous year from across all countries analyzed (Fig.1a). This result cannot be solely explained by the lockdown, as the general trend for submission to BioRxiV has been increasing exponentially since 2014 (Abdill and Blekhman 2019), thus this rise was to be expected. Although women make up a disproportionately smaller number of corresponding authors (26-28.4\%), there did not appear to be any clear difference between men and women with respect to the proportion of corresponding authorships in the time period in 2020 compared to the same period in 2019 (Fig 1b). In contrast, when we examined the data for corresponding authors with a Danish affiliation, an increase from 2019 to 2020 in total submissions was observed for men but was not observed for women in the initial month of the Danish lockdown (Fig. 1c). Consequently, the proportion of submission by gender, confirmed that for the first month of the lockdown, female scientists constituted a much smaller proportion of the corresponding authors $(13 \%)$ compared to the same time period the year before $(23 \%$, Fig $1 d)$. For the second month however, the proportions were more similar for 2020 and 2019 ( $21 \%$ vs $18 \%$, Fig 1 d).

A

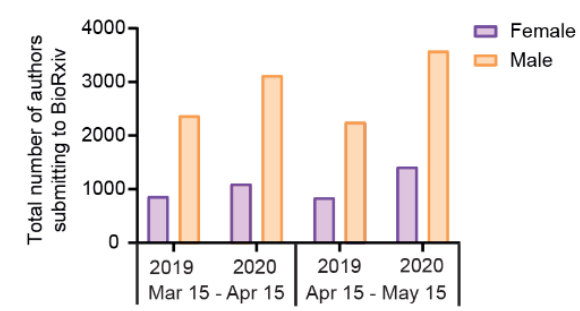

C

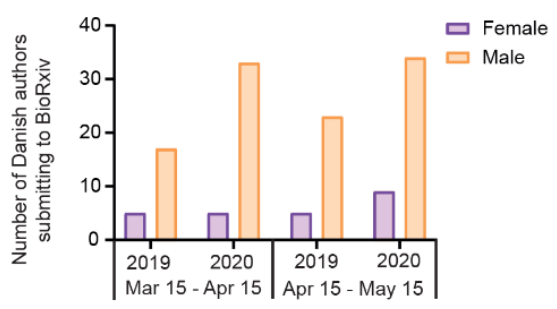

B

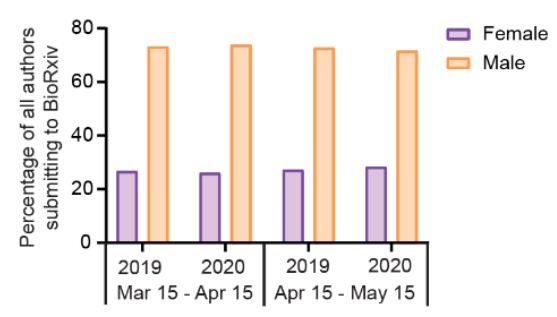

D

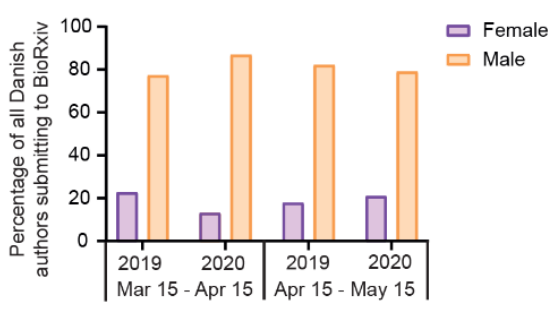

Figure 1. Analysis of corresponding authors on BioRxiV during the months of lockdown in 2020 compared to the same time in 2019. (A) The number of corresponding authors with typically male or female first names for all submissions to BioRxiV. (B) The number of corresponding authors with typically male or female first names for all submissions to BioRxiV expressed as a percentage of the total submissions. (C) The number of corresponding authors with typically male or female first names for submissions to BioRxiV with a Danish affiliation. (D) The number of corresponding authors with typically male or female first names for submissions to BioRxiV with a Danish affiliation expressed as a percentage of the total submissions. 


\section{Survey results}

The demographics of the respondents are shown in Fig 2. In total, 197 academics responded to the survey. Ten were excluded because their career stage could not be determined. The remaining responses from 75 men and 112 women were then analyzed. While all faculties were invited to participate, $93 \%$ of respondents were from the Health or Science faculties $(44.9 \%$ and $48.1 \%$ respectively). The remaining participants were from law, humanities, theology and social sciences (JUR, HUM, TEO and SAMF, respectively).

Respondents were from all career stages, with $15 \%$ being professors, $20 \%$ associate professors, $33 \%$ assistant professors or postdoctoral scientists and 32\% PhD students (Fig 2a). In this survey data, there was a significant difference between the levels of academic seniority of the male and female respondents (Chi-square analysis $\chi^{2}=8.9, \mathrm{df}=3 \mathrm{p}=0.03$ ), with a higher percentage of the male respondents being in later career stages (28\% Associate professors and 20\% professors, compared to $15 \%$ and $12 \%$ for women respectively, Fig. 2 b). However, this reflects the general representation of women at the upper and lower career stages in Danish academia.

A

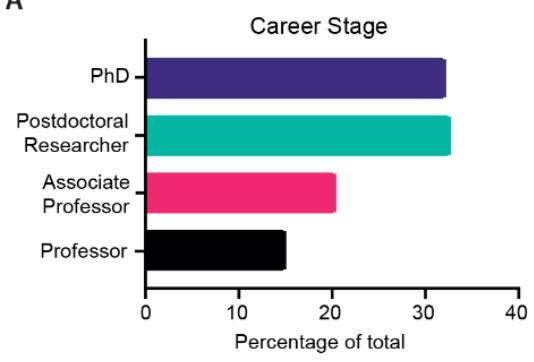

C

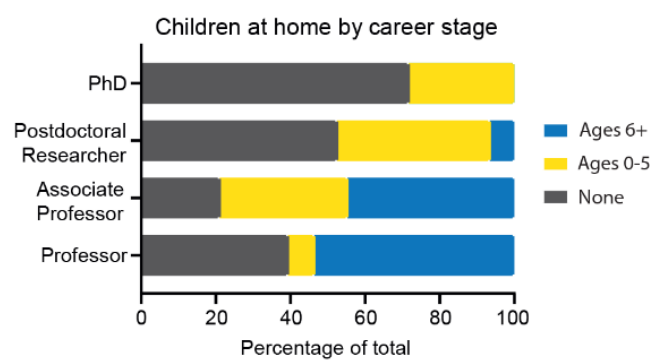

B

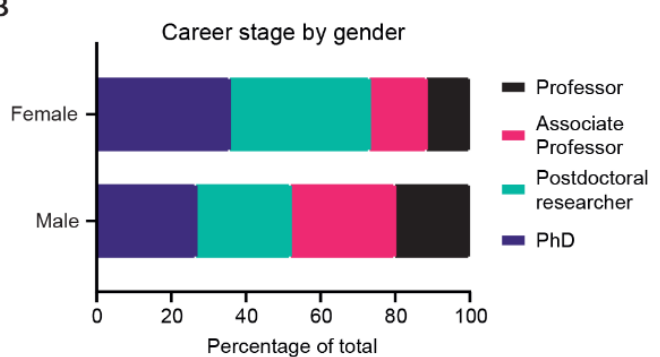

D

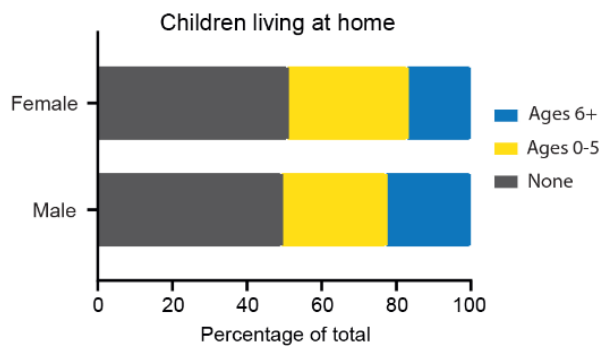

Figure 2. Demographics of Survey Respondents. (A) Career stage of respondents who indicated themselves as Ph.D. students ( $\mathrm{n}$ $=60)$, Postdoctoral Researchers/Assistant Professors $(n=61)$, Associate Professors $(n=38)$ and Professors $(n=28)$. (B) The career stage was significantly different between men and women $(p=0.03)$. The number of respondents are as follows: for women, Ph.D. students $n=40$, Postdoctoral Researchers/Assistant Professors $n=42$, Associate Professors $n=17$ and Professors $n=13$. For men, Ph.D. students $n=20$, Postdoctoral Researchers/Assistant Professors $n=19$, Associate Professors $n=21$ and Professors $n=15$. (C) Children living at home was highly dependent on career stage $(p=0.0001)$. (D) However, there was no difference in the percentage of women vs. men with children living at home in our respondents $(p=0.6)$. 
Approximately half of the respondents had children living at home and this proportion was similar for men and women (Fig 2D. Chi-square analysis $\chi^{2}=1.0, d f=2, p=0.6$ ). Those in the later career stages were more likely to have children living at home as shown in Fig. $2 \mathrm{C}$ (Chi-square analysis $\chi^{2}=$ 66.7, $d f=6, p=0.0001$ ), particularly those at the Associate Professor level. Some career stages had relatively low numbers of some career stages having children living at home between the ages of 6 12 and 12-18, thus these were combined into one group (categorized as children ages 6+).

\section{Teaching workloads increased irrespective of gender during the lockdown.}

Roughly half of the respondents had teaching duties (44\%). As the lockdown occurred during the academic teaching calendar, those with teaching responsibilities were expected, with short notice, to develop and provide new online teaching replacements. Therefore, we asked if the lockdown had caused their teaching duties to take more or less time. The vast majority (83\%) of those with teaching responsibilities reported spending more time than usual in teaching-related tasks (Fig.3). There also appeared to be a trend towards more women than men spending more time on teaching (89\% vs $75 \%$, respectively (Chi-square analysis $\chi^{2}=2.848, d f=1, p=0.0915$, Fig. 3).

\section{Reduced perceived productivity of early career researchers compared to more senior researchers.}

We asked if people generally felt more or less productive during this time. A large majority of both men $(69 \%)$ and women $(77.7 \%)$ reported being less productive than normal with only $6.7 \%$ men and $4.5 \%$ women perceiving themselves to be more productive (Fig 4a, Chi-square analysis $\chi^{2}=1.6, d f=2, p=0.4$ ). Having children did not, per se, appear to influence perceived productivity, with the exception of those with children $<5$ years old, with $92 \%$ reporting to feel less productive (Fig.4b, Chi-square analysis $\chi^{2}=8.9$, df

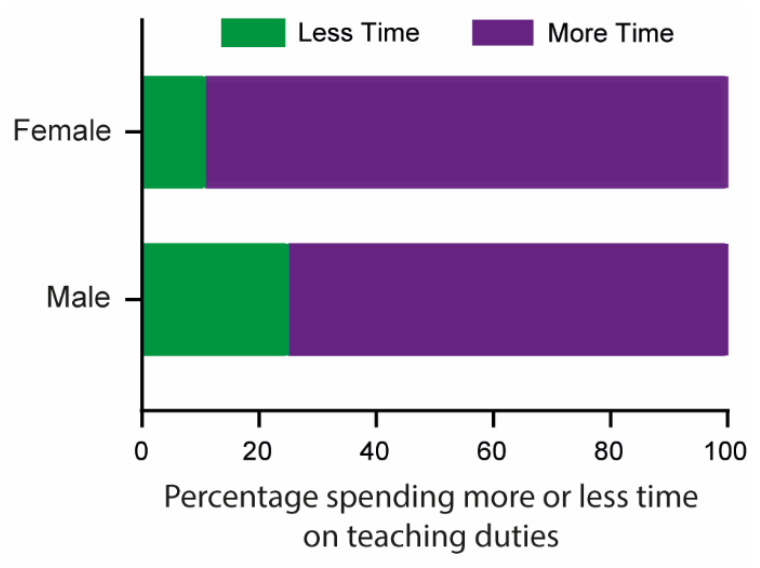

Figure 3. Respondents with teaching responsibilities reported more time spent teaching overall. For men with teaching responsibilities $n=36$ and for women $n=46$. $=4, p=0.06$ ). Out of the 59 respondents with children between the ages of 0 and 5 living at home, only 5 people reported feeling about the same level of productivity ( 3 men and 2 women) while the 
remainder reported feeling less productive. Career stage had a clearer and more significant effect on perceived productivity (Fig $4 c$, Chi-square analysis $\chi^{2}=66.7, d f=6, p=0.0001$ ), where some of those in the later, more stable career stages (associate professor and professor levels) felt more productive, whereas those in the most precarious career stages (Ph.D. student and postdoctoral researchers), felt less productive.

A

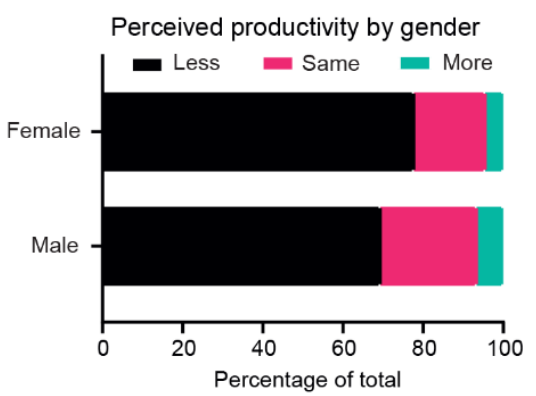

B

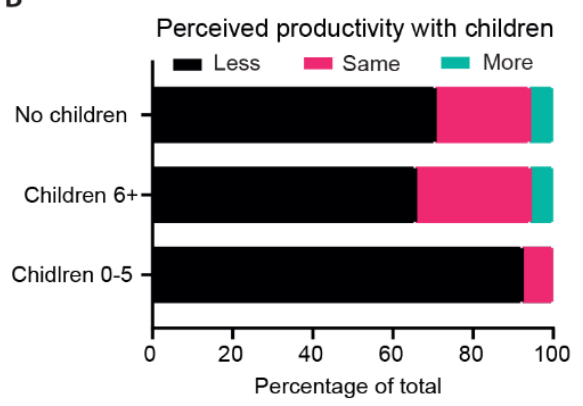

C

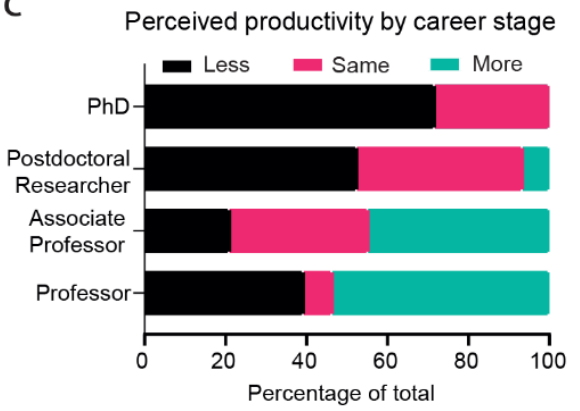

Figure 4. Self-rated productivity levels. (A) Both women $(n=112)$ and men $(n=$ 75) tended to rate themselves as less productive overall and there was no gender difference $(p=0.4)$. (B) Those with children under the age of 5 years old $(n=39)$ showed a trend $(p=0.06)$ to more often rate themselves as less productive than those with no children $(n=51)$ and children older than 6 years of age $(n=35)$. (C) Those in earlier career stages, Ph.D. $(n=60)$ and Postdoctoral researchers $(n$ $=61$ ) were much more likely $(p=0.0001)$ to rate themselves as less productive than their more senior counterparts, the Associate $(n=38)$ and full Professors $(n$ $=28$ ).

\section{Female researchers with children had fewer working hours than others.}

The respondents were asked to estimate the number of hours they were able to work during the day during the lockdown. In general, both women and men estimated that they worked a similar number of hours (Chi-square analysis $\chi^{2}=3.7, d f=2, p=0.2$ ). However, for both men and women, having children at home had a significant impact on their working hours (Fig 5A shows the data for 
women: Chi-square analysis $\chi^{2}=26.6, d f=4, p=0.0001$, Fig 5B shows the data for men: Chi-square analysis $\chi^{2}=12.2, d f=4, p=0.02$ ). Yet, if you compare the estimated working hours of men and women with children at home, regardless of age, there is a significant effect of gender, where women with children at home estimated that they were worked fewer hours at home than men with children at home (Fig5c, Chi-square analysis $\chi^{2}=6.8, \mathrm{df}=2, \mathrm{p}=0.03$ ).

A

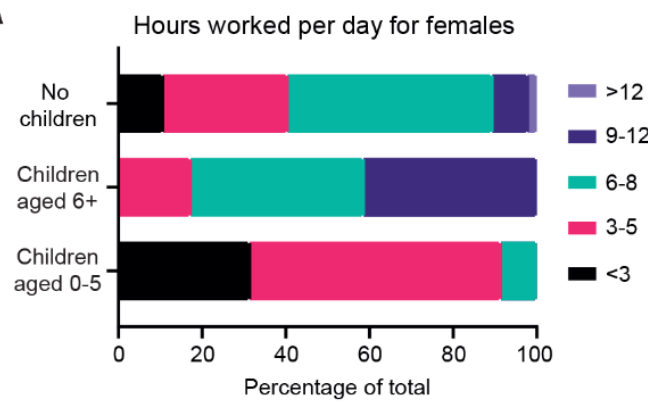

B

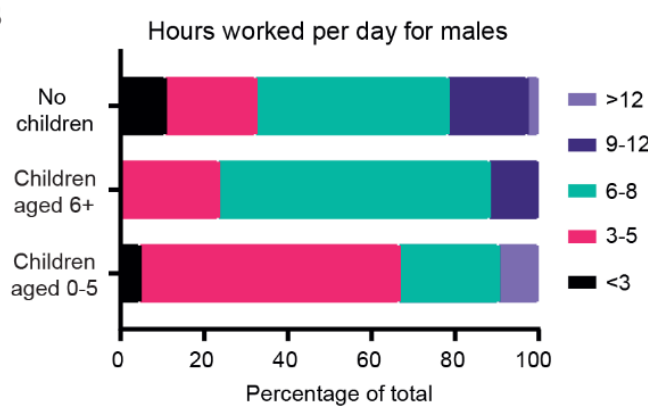

C

Hours worked per day by gender and child status

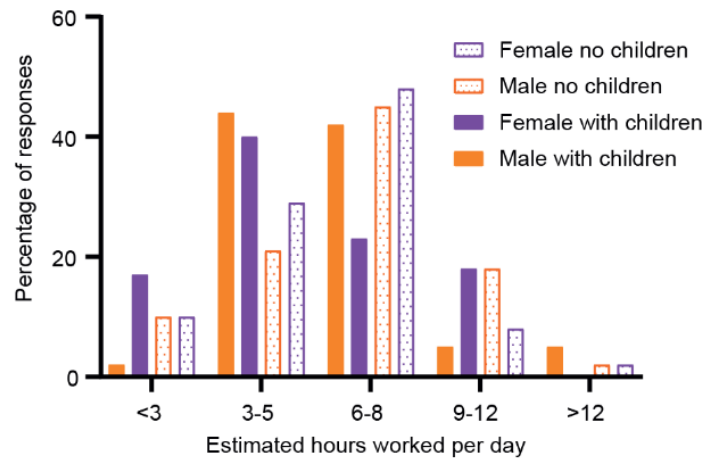

Figure 5. Estimated number of hours worked each day during the lockdown. (A) For women, those with children under the age of 5 years old $(n=35)$ estimated working less hours $(p=0.0001)$ than those with no children $(n=47)$ and children older than $6(n=$ 29). (B) For men, those with children under the age of 5 years old $(n=21)$ also estimated working less hours $(p=0.02)$ than those with no children $(n=37)$ and children older than $6(n=17)$. (C) By pooling together all women and men with children we can see a clear curve where the majority of those without children estimated working between 6-8 hours a day and the majority of those with children estimate being able to work only 3-5 hours a day 
Grant submission remained constant during the first months of lockdown, while the number of manuscripts submitted declined.

Finally, the respondents were asked to measure their productivity by research outputs in the form of publications and grants. For this analysis, the PhD group was excluded as most did not submit any publications $(77 \%)$ or grants $(83 \%)$ in 2019 , as is typical at that career stage. With respect to the number of publications (Fig 6a), there was no significant effect of gender (two-way ANOVA, F(1,248) $\left.=0.2, p=0.6, \eta_{p}^{2}=0.011\right)$, however, but there was a significant effect for year, indicating that fewer publications were submitted overall in 2020 than in 2019 (two-way ANOVA, $F(1,248)=4.0, p=0.047$ ,$\eta_{p}^{2}=0$ ). There was no significant interaction between these two variables (two-way ANOVA, $\left.F(1,248)=0.02, p=0.9, \eta_{p}^{2}=0\right)$ nor any significance following following Sidaks post-hoc analysis.

For the number of grant applications submitted by postdoctoral researcher or more senior (Fig 6b), there was no significant effect of gender (two-way ANOVA, $F(1,248)=0.6, p=0.4, \eta_{p}^{2}=0.03$ ) or year (two-way ANOVA, $F(1,248)=0.02, p=0.9, \eta_{p}^{2}=0$ ) and there was no interaction between the two variables (two-way ANOVA, $F(1,248)=0.07, p=0.8, \eta_{p}{ }^{2}=0$ ). No significant effects were found following Sidaks post-hoc analysis.

A

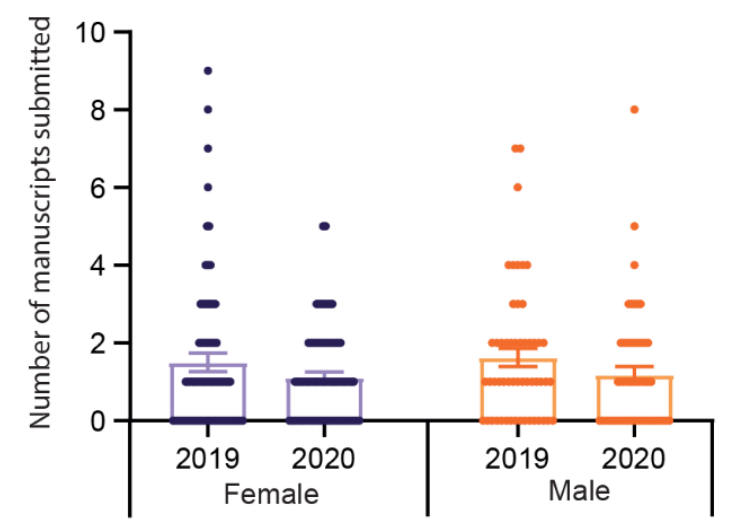

B

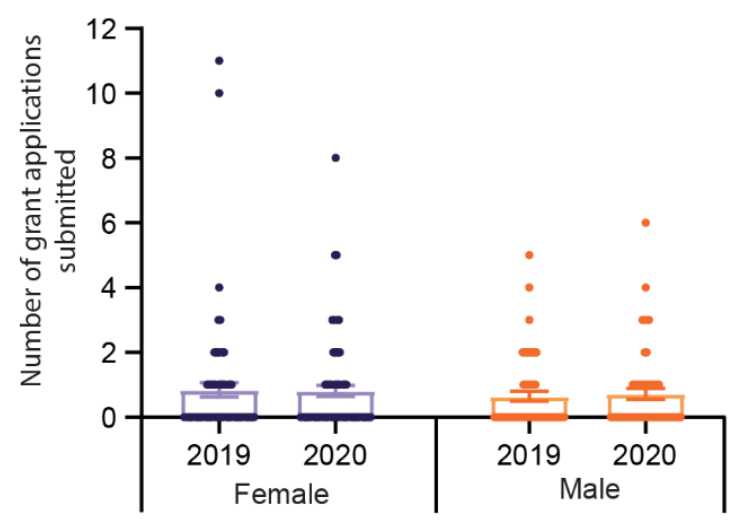

Figure 6. Number of publications and grants submitted in the period of March 13 to May 10 in 2019 compared to the same period in 2020 , during the lockdown. (A) The number of publications submitted by women ( $n=72$ respondents) and men ( $n=54$ respondents) at the career level of postdoctoral researcher or more senior in 2019 was slightly higher than in 2020 ( $p=0.047$ ). There was no significant effect of gender on this measure. (B) For the number of grants submitted by the same group of respondents there was not significant effect of year or gender. 


\section{Discussion}

Our results show that that there were clear differences on the consequences of the lockdown for productivity depending on whether researchers had young children at home, whether they had teaching responsibilities and, importantly, depending on their gender. To understand the reduction in productivity of female researchers revealed by this study in context, below, we expand on three contextual foci: family structures, academic organizing, and the Danish context vis-à-vis Denmark's international reputation.

\section{Family structures}

Firstly, the analysis showed that women submitted fewer preprints as corresponding authors than men in the first month of the lockdown compared with the same time period the year before ( $13 \%$ vs $23 \%$ ). We further found that having children per se did not appear to influence perceived productivity with the exception of those with children $\leq 5$ years old. $92 \%$ of this group reported perceiving themselves as less productive. For both men and women, having children at home had a significant impact on their working hours. However, women with children at home estimated that they could worked less hours at home than men with children at home.

It is important to note that women living in heterosexual relationships with children by no means account for the circumstances of all female researchers, however, this traditional family structure remains the norm in Denmark (Borchorst, 2004). This traditional norm implies that, while both partners work, the male's career often takes precedence, and women continue to take on more house and care work than men (Cevea, 2016). Disparity in care-related work is especially evident in parental leave in relation to childbirth $^{1}$ (Statistics Denmark, 2019a,b), which is known to influence the division domestic duties, thus, reinforcing the traditional gender roles (Cederström, 2019; Damm \& Kirkbak, 2020). Finally, part-time work contracts, typically used to accommodate childcare needs, are much more prevalent among Danish women than men $^{2}$ (Teigen \& Skeije, 2017). Although part-time working arrangements are generally less prevalent in academia than in other occupations,

\footnotetext{
${ }^{1}$ In 2018, Danish mothers held on average 278.9 days of maternity leave, whereas Danish fathers held on in average 40 days (Statistics Denmark, 2019)

${ }^{2}$ In 2014, 15 per cent of Danish men worked part time compared with 35 per cent of Danish women (Teigen \& Skeije, 2017).
} 
they are not unheard of. Based on the above contextual factors, it is certainly plausible that during the Danish COVID-19 lockdown, academic couples may have defaulted to a similarly skewed arrangement with adverse consequences for women's productivity. Although our survey data can only inform us about the survey participants' self-reported productivity and care work, it is further important to mention that there is a tendency for Danish women and men to disagree on the level of equality in the home. That is, men tend to overestimate their contribution to domestic duties compared with women's perceived estimation of their male partner's executed domestic workload (Cederström, 2019). Finally, we note that some of the surveyed participants would have been international scholars employed at Copenhagen University. Family structures may differ based on cultural norms, and individual families may organize themselves in non-traditional ways with respect to professional and domestic/care work. Here, we can only speak to general tendencies to interpret of the findings of this study.

That the difference between 2020 and 2019 in terms of women's submissions of preprints as corresponding authors evened out from March to April (13\% compared with $20 \%$ for March, and $21 \%$ compared with $18 \%$ for April) could suggest that a re-negotiation of the division of labour during lockdown may have taken place. However, we abstain from making any conclusions on this point.

\section{Academic organizing}

\section{Research versus teaching responsibilities}

According to our analysis, of those participants with teaching obligations, the vast majority reported spending more time on teaching, which is unsurprising given the short notice of converting face-toface lectures to online formats. However, feminist scholarship on gender inequalities in academia makes evident that different aspects of academic work carry different gendered meanings, with publication (masculine connotations of accomplishment and ambition) ranking highest and undergraduate teaching (feminine connotations of care and communication) ranking lowest (Leta, et al, 2013). It is further widely accepted that publications are more easily translatable into academic career 'capital', which is not equally accessible to all (Ibid). Research points to a tendency that female academics appreciate and prioritize teaching and supervision activities more than their male 
counterparts (Winslow, 2010), and that teaching more often simply falls on women as the 'housewives' of academia (Angervall \& Beach, 2017, 2020). Such factors are crucial to consider when interpreting the result of our analysis, as different academic work tasks are already fundamentally gendered and, based on this study, skewed. Other factors may also play a role in determining who are affected by the transition to remote teaching, and how they are affected. For example, senior scholars with decades of teaching experience may have an extensive catalogue of lecture content to fall back on, whereas junior scholars may be more tech savvy.

While article manuscripts can be submitted all year round, the Danish lockdown occurred at a pivotal time in the academic calendar, when many research foundations had critical annual application deadlines for calls for potentially career defining grants (including starting and ascending investigator grants). Despite this, this study found no difference in number of grants submitted in 2020 compared with 2019. Further research is therefore warranted to determine the extent to which researchers may have prioritized grant applications over article submission during the lockdown, as childcare and increased teaching-related pressures may not have permitted undertaking both. Furthermore, over the last decade, Danish academia has changed considerably with the emergence of focused research centers where researchers often have only minimal or no teaching responsibilities. Researchers working in the same institutions but in the traditional teaching departments with considerably higher teaching loads already must compete against these centers for funding, and would thus being even further disadvantaged by the increased teaching burden at this critical time. Based on the Swedish context, Angervall and Beach (2020) state that women more likely to work in the less research-intensive centers and departments, as well as in what they term - 'teaching intensive academic fields' such the social sciences and humanities. As the latter point certainly applies to the Danish academy (Danish Ministry of Education and Science, 2020), a gendered imbalance could be assumed that may affect the aggregate success rate for grant applications. To date, there are no analyses have been published regarding the gender distribution of staff at teaching versus research-intensive departments in Denmark, which warrants further investigation. 


\section{Denmark's international reputation}

From the outset, Denmark seems to tick all the boxes to ensure gender parity, including appropriate legislation and the structures necessary to facilitate women's equal participation in the labour market (Borchorst, 2009; Borchorst \& Siim, 2008). However, when it comes to gender equality, Denmark constitutes an interesting and contradictory case. It simultaneously tops international gender equality rankings and falls noticeably behind with respect to on occupation-related metrics (Utoft, 2020a), especially when compared with the other Nordic countries (Teigen \& Skjeie, 2017; Borchorst \& Dahlerup, 2020). The gender distribution of parental leave days, as discussed above, is one example, others include the low share of women in executive roles in the private sector, political participation (World Economic Forum, 2019) and in the STEM fields (Danish Ministry of Education and Science, 2020). Furthermore, the Danish culture pertaining to gender equality sets the country apart. Danes demonstrate comparatively high levels of 'perceived gender equality', i.e., a trust that gender discrimination is eliminated in all spheres of private and public life ${ }^{3}$ (Borchorst \& Dahlerup, 2020; Utoft, 2020b), despite evidence to the contrary including the tentative results of this study.

The results regarding corresponding authors from Denmark did not mirror the international averages for BioXriv with a clear reduction in the proportion of female corresponding authors submitting papers in the first month of the lockdown. This difference, compared to the international data might suggest that Danish female scientists were proportionally more affected by the initial lockdown than in other countries. This conclusion, however, must be tempered by the fact that the timing, duration, and severity of COVID-19 lockdowns differed across the globe. For example, in Denmark, the first lockdown was comparatively short (2 months), which complicates analysis of international data. Comparison of similar data in respect to corresponding authors from US institutions submitting to BioRxiv did appear to confirm that Danish female scientists were more affected than in the US. It is noteworthy that the total numbers of submissions were low, and, more importantly, reflect manuscripts predominantly prepared prior to the lockdown. Therefore, it is

\footnotetext{
${ }^{3}$ Also known as 'modern sexism' which is correlated with backlash and resentment towards gender equity demands (such as gender equality interventions) (see Skewes, Fine \& Haslam, 2018; Skewes, Skewes \& Ryan, 2019).
} 
important that further research is performed to follow-up on the data presented within this study to determine the long-term effects of COVID-19 lockdowns on academic productivity.

\section{Concluding remarks and implications}

In this study, it was investigated whether female researcher in Denmark were disproportionately affected by the first COVID-19 lockdown compared to men. This research question was examined by an analysis of manuscript submissions to the preprint server BioRxiv, focusing on corresponding authors from Danish institutions, and through a survey of researchers (ay different academic levels) at the University of Copenhagen. The main results indicate that both men and women with younger children as well as those with teaching responsibilities were disproportionally affected by the lockdown. However, female researchers with younger children tended to be more affected than their corresponding male colleagues.

In the above discussion, the findings were contextualized to unfold the structural and cultural factors (domestic and institutional) that influence how and to what extent different researchers are affected in the professional and personal life by such a disruption like a global pandemic. Whilst the long-term consequences of the first lockdown upon female researchers is yet to be determined, the more immediate consequences for individual women's careers, especially early-career researchers could soon be apparent. In general, Danish universities profess to ambitions of improving the representation of women among tenured faculty, and most institutions work with gender equality or diversity plans to realize this ambition (Danish Ministry of Education and Science, 2020). It is worrisome that the pandemic may be magnify pre-existing inequalities. To counter this problem, it will be crucial for universities to incorporate measures that fairly evaluate the qualifications of candidates, takin the differential effects of the lockdowns into account.

Furthermore, this study presents a narrow focus on female researchers with an assumption that women with children are in heterosexual relationships, which we admit does not represent the whole picture. Singles, sole parents, and same-sex couples with children, may experience 
disproportionate effects on professional productivity during the lockdown. However, in general, this study demonstrates that the vast majority of researchers surveyed felt less productive during the first lockdown, with more time spent on teaching commitments. Despite this, in general, many managed to maintain grant submission, and eventually increase publication submission. This reveals a real risk of burn-out amongst academics as a consequence of the radical changes to people's domestic and professional lives. Especially, it is noteworthy that the Ph.D. students and postdoc scientists surveyed reported feelings of less productivity. While reduced perceived productivity is different from burn-out, the consequence of both may result in a lack of motivation, increased stress levels, and reduced research output. Reduced supervision or lack of access to laboratories and necessary equipment during lockdown is likely to affect early-career researchers' productivity. For Ph.D. students and postdoc scientists in short, fixed-term contracts, publication success is critical for employment. For these early career researchers, precarious working conditions are already stressful, to which the lockdown may have amplified their feelings of performance anxiety and career uncertainty. However, any further reflections on this point are beyond the scope of this article.

This study presents a brief snapshot of the immediate impact of the first COVID-19 lockdown in Denmark. Since this survey, Denmark has experienced its second lockdown and several of the largest universities have announced predominately online teaching from January to April 2021. The effect that we saw in our limited timeframe thus reflects the tip of the iceberg. Future research will be needed to evaluate the long-term consequences of COVID-19 lockdowns not only in terms of productivity but also the psychological impact on research and teaching staff. 


\section{References}

Abdill RJ, Blekhman R. (2019). Tracking the popularity and outcomes of all bioRxiv preprints. Elife. 2019 Apr 24;8:e45133.

Angervall, P., and D. Beach. (2017). "The Exploitation of Academic Work: Women in Teaching at Swedish Universities." Higher Education Policy. Advance online publication. doi:10.1057/s41307- 017-0041-0.

Angervall P and Beach D. (2020) Dividing academic work: gender and academic career at Swedish universities, Gender and Education, 32:3, 347-362

Bendixen M and Hall VJ ( 2020) How the pandemic could choke gender equity for female researchers in Denmark. Nature. Career Column Sep 9.

Borchorst, A. (2004) Den kønnede virkelighed - den kønsløse debat. In: J. G. Andersen (ed.) Den demokratiske udfordring (113-132). Copenhagen: Hans Reitzels.

Borchorst, A. (2009) Scandinavian gender equality: Competing discourses and paradoxes. Aalborg: Institut for Historie, Internationale Studier og Samfundsforhold, Aalborg Universitet. FREIA's tekstserie, No. 69. Retrieved from https://vbn.aau.dk/ws/portalfiles/portal/16672755/freia wp 69.pdf

Borchorst, A., \& Siim, B. (2008). Woman-friendly policies and state feminism-Theorizing Scandinavian gender equality. Feminist Theory, 9, 207-224.

Borchorst, A., \& Dahlerup, D. (2020). Konflikt og konsensus: Det danske ligestillingspolitiske regime. Copenhagen: Frydenlund.

Cederström, C. (2019) State of Nordic Fathers. Nordic Council of Ministers. Retrieved from: http://norden.diva-portal.org/smash/get/diva2:1367228/FULLTEXT01.pdf. doi.org/10.6027/NO2019-044

Cevea (2016) Det kønsopdelte arbejdsmarked. Retrieved from https://cevea.dk/analyse/det-konsopdeltearbejdsmarked/

Damm EA \& Kirkbak J (2020) Mødre bliver oftere hjemme, når børnene er syge. Arbejderbevægelsens Erhvervsrå. Retrieved from: https://ae.dk/sites/www.ae.dk/files/dokumenter/analyse/ae moedre-bliveroftere-hjemme-naar-boernene-er-syge.pdf

Danish Ministry of Education and Science (2020) Mænd og kvinder på de danske universiteter: Danmarks talentbarometer 2019. Retrieved from: https://ufm.dk/publikationer/2020/maend-og-kvinder-pa-dedanske-universiteter-danmarks-talentbarometer-2019

Frederickson M, (2020). COVID-19's gendered impact on academic productivity. Retrieved from: https://github.com/drfreder/pandemic-pub-bias/blob/master/README.md

Hansen, D.S. (2020). Identifying Barriers to Career Progression for Women in Science: Is COVID-19 Creating New Challenges?. Trends Parasitol. 2020 Oct;36(10):799-802.

Leta, J., G. Olinto, P. Batista, and E. Borges. (2013). "Gender and Academic Roles in Graduate Programs: Analyses of Brazilian Government Data." In Proceedings of ISSI 2013, Vienna, Volume 1, edited by J. Gorraiz, E. Schiebel, C. Gumpenberger, M. Hörlesberger, and H. Moed, 796-810. Vienna: Facultas Verlags- und Buchhandels AG. 
Malisch JL, Harris BN, Sherrer SM, Lewis KA, Shepherd SL, McCarthy PC, Spott JL, Karam EP, MoustaidMoussa N, Calarco JM, Ramalingam L, Talley AE, Cañas-Carrell JE, Ardon-Dryer K, Weiser DA, Bernal XE, Deitloff J. (2020). Opinion: In the wake of COVID-19, academia needs new solutions to ensure gender equity. Proceedings of the National Academy of Sciences Jul 2020, 117 (27) 15378-15381.

Nielsen MW, Andersen JP, Schiebinger $L$, et al . One and a half million medical papers reveal a link between author gender and attention to gender and sex analysis. Nat Hum Behav 2017;1:791-6.

Oleschuk, M. (2020). Gender Equity Considerations for Tenure and Promotion during COVID-19. Can Rev Sociol. 2020 Aug;57(3):502-515.

Organization for Economic Cooperation and Development [OECD] (2018). Balancing Paid Work, Unpaid W Retrieved from: https://www.oecd.org/gender/balancing-paid-work-unpaid-work-and-leisure.htm

Pinho-Gomes A-C, Peters S, Thompson K, Hockman C, Ripullone, K, Woodward M, Carcek C. (2020) Where are the women? Gender inequalities in COVID-19 research authorship. BMJ Global Health2020;5:e002922.

Skewes, L., Fine, C. \& Haslam, N. (2018) Beyond Mars and Venus: The role of gender essentialism in support for gender inequality and backlash. PloS one, 13(7), 1-17.

Skewes, L., Skewes, J., \& Ryan, M. (2019) Attitudes to Sexism and Gender Equity at a Danish University. Kvinder, Køn \& Forskning, 28(1-2), 71-85.

Statistics Denmark (2019a). Maternity benefits. Retrived from: https://www.dst.dk/en/Statistik/emner/levevilkaar/offentligt-forsoergede/barselsdagpenge

Statistics Denmark (2019b) Ligestilling i Danmark - Familie. Retrived from: https://www.dst.dk/da/Statistik/emner/levevilkaar/ligestilling/ligestillingswebsite\#1

Teigen, M. \& Skjeie, H. (2017) The Nordic gender equality model. In O. Knutsen (ed.) The Nordic models in political science: Challenged but still viable? (125-148). Oslo: Fagbokforlaget. Retrieved from: https://www.samfunnsforskning.no/core/bilder/artikler/the-nordic-gender-equality-model.-comparingscores-\%28short-version\%29.pdf

Utoft, E. H. (2020a). Motivation, organisational gender equality work and the postfeminist gender regime: A feminist approach (Politicas PhD Series). Department of Political Science, Aarhus University, Aarhus, Denmark. Retrieved from https://politica.dk/politicas-phd-serie/

Utoft, E. H. (2020b). Manoeuvring within postfeminism: A study of gender equality practitioners in Danish academia. Gender, Work \& Organization. 27: 778-787

Vincent-Lamarre, P. , Sugimoto C.R. and Larivière V.. 2020. The Decline of Women's Research Production during the Coronavirus Pandemic." Nature Index. Retrieved from:https://www.natureindex.com/newsblog/decline-women-scientist-research-publishing-production-coronavirus-pandemic.

Werner MR, Li Y, MS and Nead KT (2020). Comparison of the Proportions of Female and Male Corresponding Authors in Preprint Research Repositories Before and During the COVID-19 Pandemic. Research Letter. Medical Journals and Publishing. JAMA Netw Open. 2020;3(9):e2020335.

Winslow, S. (2010). Gender inequality and time allocations among academic faculty. Gender \& Society, 24(6), 769-793. 
World Economic Forum (2018). The Global Gender Gap Report 2018. Retrieved from https://www.weforum.org/reports/the-global-gender-gap-report-2018 


\section{Appendix}

\begin{tabular}{|c|c|}
\hline Questions & Response options \\
\hline \multirow[t]{3}{*}{ Which faculty are you in } & Health science \\
\hline & Natural Science \\
\hline & Humanities \\
\hline \multirow[t]{5}{*}{ What career stage are you? } & Ph.D. student \\
\hline & Postdoctoral researcher/adjunkt \\
\hline & Associate Professor/lektor \\
\hline & Professor \\
\hline & Other \\
\hline \multirow[t]{4}{*}{ Gender } & Male \\
\hline & Female \\
\hline & Non-binary \\
\hline & Prefer not to say \\
\hline \multirow[t]{4}{*}{ Do you have children living at home? } & Yes, age $1-5$ \\
\hline & Yes, age 5-12 \\
\hline & Yes, age $12-18$ \\
\hline & No \\
\hline \multirow{5}{*}{$\begin{array}{l}\text { How many hours have you realistically been working per } \\
\text { day from home? }\end{array}$} & Less than 3 \\
\hline & $3-5$ \\
\hline & $5-8$ \\
\hline & $8-12$ \\
\hline & $12+$ \\
\hline \multirow{4}{*}{$\begin{array}{l}\text { If you have teaching obligations do you feel these have } \\
\text { taken }\end{array}$} & More time than usual \\
\hline & The same time as usual \\
\hline & Less time than usual \\
\hline & I do not have teaching obligations \\
\hline \multirow{7}{*}{$\begin{array}{l}\text { During the dates of March } 13 \text { to May } 10 \text { this year how } \\
\text { many of the following have you submitted: }\end{array}$} & Research papers (submitted yourself) \\
\hline & Research papers (other author submitted) \\
\hline & Review articles (submitted yourself) \\
\hline & Review articles (other author submitted) \\
\hline & Book chapters \\
\hline & Grant applications (as main applicant) \\
\hline & Grant applications (as co-applicant) \\
\hline
\end{tabular}




\begin{tabular}{|l|l|}
\hline \multirow{2}{*}{$\begin{array}{l}\text { During the dates of March } 13 \text { to May } 10 \text { last year how } \\
\text { many the following did you submit: }\end{array}$} & Research papers (submitted yourself) \\
\cline { 2 - 2 } & Research papers (other author submitted) \\
\cline { 2 - 2 } & Review articles (submitted yourself) \\
\cline { 2 - 2 } & Review articles (other author submitted) \\
\cline { 2 - 2 } & Book chapters \\
\cline { 2 - 2 } & Grant applications (as main applicant) \\
\cline { 2 - 2 } & Grant applications (as co-applicant) \\
\hline Do you generally feel you are: & More productive than usual \\
\cline { 2 - 2 } & Less productive than usual \\
\cline { 2 - 2 } & About as productive as before. \\
\hline
\end{tabular}

Table 1: Survey distributed to researchers at the University of Copenhagen. 